University of Wollongong

Research Online

Faculty of Engineering and Information

Faculty of Engineering and Information

Sciences - Papers: Part A

Sciences

$1-1-2015$

\title{
Field investigation on compaction and strength performance of two coal wash-BOS slag mixtures
}

\author{
S.M.Ali Tasalloti \\ University of Wollongong, smat777@uowmail.edu.au \\ Buddhima Indraratna \\ University of Wollongong, indra@uow.edu.au \\ Gabriele Chiaro \\ University of Tokyo, gchiaro@uow.edu.au \\ Ana Heitor \\ University of Wollongong, aheitor@uow.edu.au
}

Follow this and additional works at: https://ro.uow.edu.au/eispapers

Part of the Engineering Commons, and the Science and Technology Studies Commons

Research Online is the open access institutional repository for the University of Wollongong. For further information contact the UOW Library: research-pubs@uow.edu.au 


\title{
Field investigation on compaction and strength performance of two coal wash- BOS slag mixtures
}

\author{
Abstract \\ The effective reuse and recycling of industrial byproducts, namely coal wash (CW) and basic oxygen steel \\ slag (BOS), through large-scale geotechnical projects (e.g. land and port reclamation) is economically \\ beneficial and environmentally sustainable. Nevertheless, due to the heterogeneity of these granular \\ waste materials, the actual performance of compacted fill in the field can be significantly different from \\ that observed in the laboratory. This paper reports the results of a compaction field trial carried out at \\ Port Kembla Outer Harbor reclamation site (Wollongong, Australia) to evaluate the in situ performance of \\ two selected CW-BOS blends. Based on a number of field density tests, it was found that 4 passes of \\ compaction were adequate for achieving a fill density $>90 \%$ standard Proctor compaction. A series of \\ dynamic cone penetration tests (DCPTs) confirmed that compacted CW-BOS fills have a greater strength \\ compared to compacted sandy fill, as the number of blows to penetrate $100 \mathrm{~mm}$ is greater than 20 for \\ both materials. Furthermore, plate load tests were also performed and swelling was routinely monitored. \\ The results are presented and discussed.

\section{Disciplines} \\ Engineering | Science and Technology Studies

\section{Publication Details} \\ Tasalloti, S., Indraratna, B., Chiaro, G. \& Heitor, A. (2015). Field investigation on compaction and strength \\ performance of two coal wash-BOS slag mixtures. In M. Iskander, M. T. Suleiman, J. Anderson \& D. F. \\ Laefer (Eds.), Geotechnical Special Publication (pp. 2359-2368). United States: American Society of Civil \\ Engineers.
}




\title{
Field Investigation on Compaction and Strength Performance of Two Coal Wash-BOS Slag Mixtures
}

\author{
S.M.Ali Tasalloti ${ }^{1}$, A.M. ASCE, Buddhima Indraratna ${ }^{2}$, F. ASCE, Gabriele Chiaro ${ }^{3}$, \\ and Ana Heitor ${ }^{4}$ \\ ${ }^{1} \mathrm{PhD}$ Candidate, School of Civil, Mining and Environmental Engineering, University \\ of Wollongong, Wollongong, NSW 2522, Australia (smat777@uowmail.edu.au) \\ ${ }^{2}$ Professor of Civil, Mining and Environmental Engineering, Research Director of \\ Centre for Geomechanics and Railway Engineering, University of Wollongong, \\ Wollongong, NSW 2522, Australia (indra@uow.edu.au) \\ ${ }^{3}$ JSPS Research Fellow, Geo-disaster Mitigation Engineering Laboratory, Institute of \\ Industrial Science, The University of Tokyo Be205, 4-6-1 Komaba, Meguro-ku, 153- \\ 8505 Tokyo, Japan; formerly, ARC Research Fellow, Centre for Geomechanics and \\ Railway Engineering, University of Wollongong, (gabichiaro@yahoo.it) \\ ${ }^{4}$ Lecturer, School of Civil, Mining and Environmental Engineering, University of \\ Wollongong, Wollongong, NSW 2522, Australia (aheitor@uow.edu.au)
}

\begin{abstract}
The effective reuse and recycling of industrial byproducts, namely coal wash (CW) and Basic Oxygen Steel slag (BOS), through large-scale geotechnical projects (e.g. land and port reclamation) is economically beneficial and environmentally sustainable. Nevertheless, due to the heterogeneity of these granular waste materials, the actual performance of compacted fill in the field can be significantly different from that observed in the laboratory. This paper reports the results of a compaction field trial carried out at Port Kembla Outer Harbor reclamation site (Wollongong, Australia) to evaluate the in-situ performance of two selected CW-BOS blends. Based on a number of field density tests, it was found that 4 passes of compaction were adequate for achieving a fill density $>90 \%$ standard Proctor compaction. A series of dynamic cone penetration tests (DCPTs) confirmed that compacted CW-BOS fills have a greater strength compared to compacted sandy fill, as the number of blows to penetrate $100 \mathrm{~mm}$ is greater than 20 for both materials. Furthermore, plate load tests were also performed and swelling was routinely monitored. The results are presented and discussed.
\end{abstract}

\section{INTRODUCTION}

More than 10 million tonnes of industrial waste materials are produced annually in New South Wales (NSW), Australia. The main two byproducts in NSW region is coal wash (CW) and Blast Oxygen Steel slag (BOS) (Leventhal, 1996). These materials 
have been used in many civil applications such as road embankments, asphalt aggregates, subgrade fill (Indraratna, 1994, Malasavage et al., 2012, Indraratna et al., 2012, Rujikiatkamjorn et al., 2013). An effective reuse of these byproducts rather than disposal is economically beneficial and environmentally sustainable.

This study is included in an industrial project for Port Kembla Outer Harbor reclamation. Port Kembla is located on the east coast of Australia in Wollongong region and is one of the major ports in NSW. The need for new berthing facilities for coal mining exports and the import for other products, has been driving the expansion of the harbor (Fig. 1) which consist of 42 hectares of land reclamation (Lai et al., 2011). The two industrial byproducts (i.e. CW and BOS) were considered as a structural fill for this project. The Centre for Geomechanics and Railway Engineering of the University of Wollongong was requested to evaluate the geotechnical feasibility of these materials to be employed as structural fill. The laboratory investigation on the geotechnical properties of different mixtures of CW and BOS enabled the selection of two optimal mixtures to be used in the field trial (Chiaro et al., 2014a, Chiaro et al., 2014b,). As the in situ field performance of the optimum mixtures can be different from that of laboratory (i.e. heterogeneity nature of these materials and scale effects), it is important to monitor the behavior of the mixtures on a field trial.

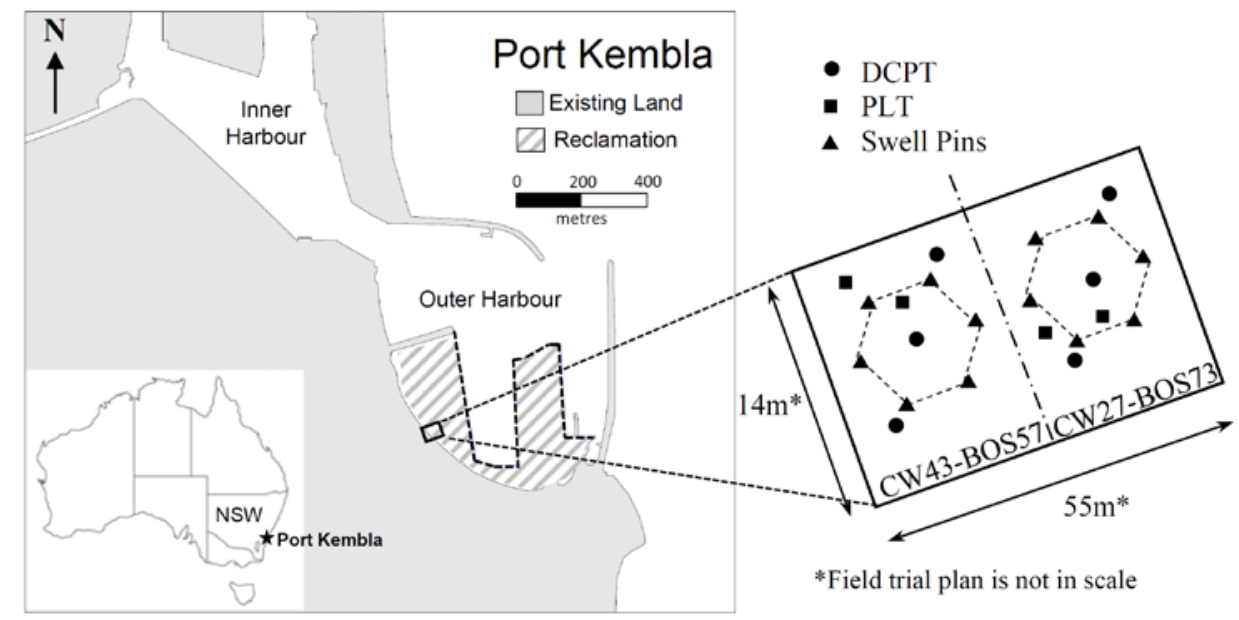

FIG 1. Layout of Port Kembla reclamation project (after Chiaro et al., 2014b)

In this paper, the results of the field trial performance of two selected mixtures of CW and BOS are presented and discussed. The in-situ density was determined for every roller pass using both the sand cone replacement method and nuclear densometer. In addition, the post compaction strength of the compacted layers and deformation behavior were evaluated using the dynamic cone penetration (DCPT) and plate load tests (PLT), respectively. The time-dependent behavior of the mixtures was observed as the strength of the materials increased with time due to the hydration reaction associated with the free lime content of BOS. Furthermore, the post compaction swelling potential was also monitored. The results of this study indicated that the optimum mixtures of $\mathrm{CW}$ and BOS used in the field trial were suitable as structural fill. 


\section{TEST MATERIALS AND PROCEDURE}

\section{Material}

Two industrial byproducts were used in the field trial, the CW; a very dark heterogeneous material produced in a local colliery and the BOS produced by the Australian Steel Mill Services. The physical properties and classification of these two materials are provided in Table 1 . It is evident that the $\mathrm{CW}$ is much lighter than silty sands fill whereas BOS is heavier. However, the mixture of these two materials shows similarity to the conventional fill materials in terms of specific gravity. Based on the USCS standard, CW and BOS are classified as GW-GM and SW, respectively. Particle size distributions of CW and BOS in the stockpile are presented in Fig. 2. Due to the adhesion of fine and coarse particles in CW, the wet sieve method was incorporated (AS 1289.3.6.1-2009).

Table 1. Physical and classification of CW and BOS source materials.

\begin{tabular}{|c|c|c|c|c|c|c|c|}
\hline \multirow{2}{*}{ Material } & $\begin{array}{l}\text { Specific } \\
\text { gravity }\end{array}$ & \multicolumn{3}{|c|}{ Particle Size } & \multirow[t]{2}{*}{ USCS } & \multirow{2}{*}{$\begin{array}{c}\text { Permeability } \\
(\mathrm{m} / \mathrm{s})\end{array}$} & \multirow{2}{*}{$\frac{\text { MDUW }}{\left(\mathrm{kN} / \mathrm{m}^{3}\right)}$} \\
\hline & - & $\begin{array}{c}\% \\
\text { gravel }\end{array}$ & $\begin{array}{c}\% \\
\text { sand }\end{array}$ & $\begin{array}{c}\% \\
\text { fines }\end{array}$ & & & \\
\hline $\mathrm{CW}$ & 2.27 & 53 & 36 & 11 & GW-GM & $5.0 \times 10^{-9}$ & 16.9 \\
\hline BOS & 3.34 & 25 & 69 & 6 & SW & $5.1 \times 10^{-7}$ & 22.7 \\
\hline
\end{tabular}

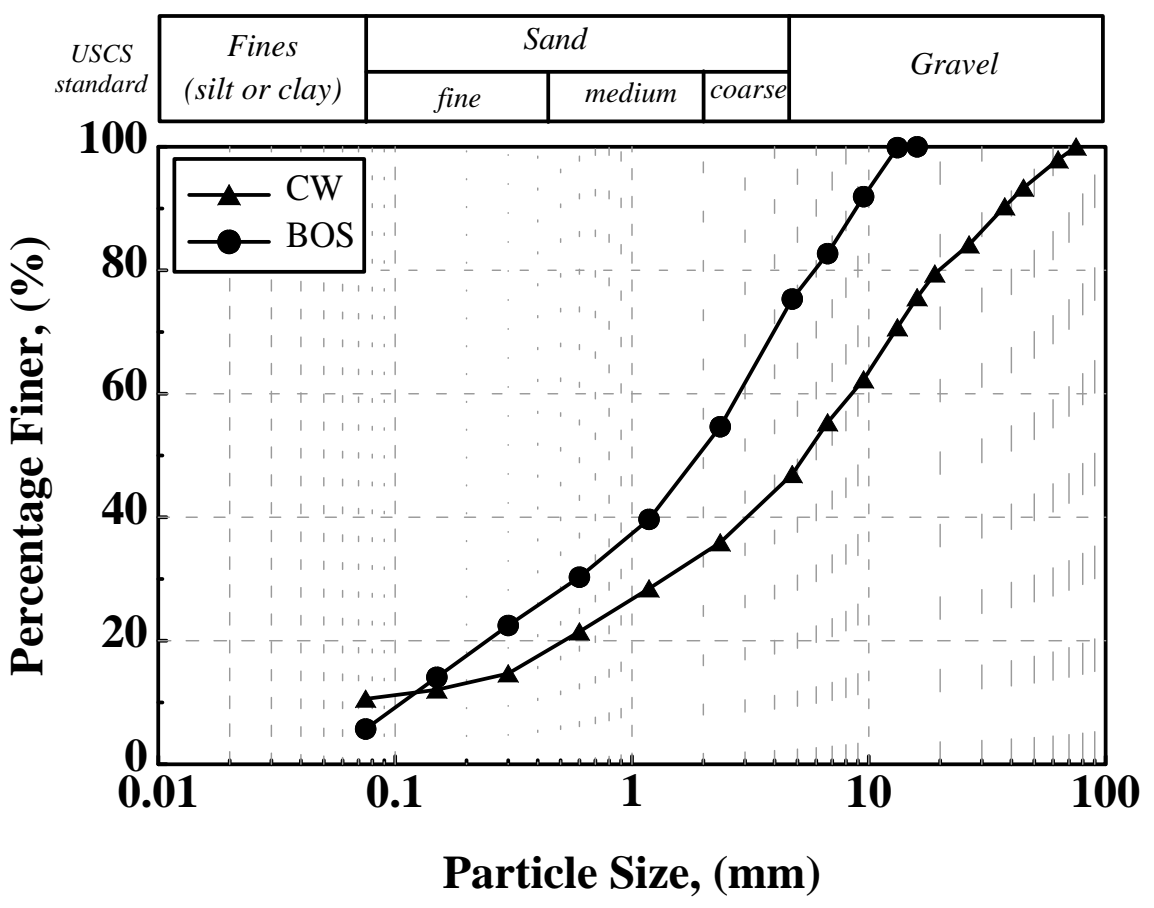

FIG 2. Particle size distribution curves for $\mathrm{CW}$ and BOS in the stockpile. 


\section{Field testing}

The field trial described in this paper was conducted at Port Kembla Outer Harbor reclamation site shown in Fig. 1 . An area of $55 \mathrm{~m}$ by $14 \mathrm{~m}$ was provided by Port Kembla Port Corporation (PKPC) for the field trial, and the depth of layer was $1.4 \mathrm{~m}$ (i.e. total volume of $1078 \mathrm{~m}^{3}$ ). The area was divided into two equal parts to assess the performance of two selected mixtures CW43-BOS57 and CW27-BOS73 prepared by weight percentage, which is equivalent CW50-BOS50 and CW20-BOS80 by volume percentage, respectively. In laboratory, typically the mixes are prepared by weight, but given the difficulty associated with preparing those mixes by weight in the field, a volume ratio was adopted instead. The mixing and placing of the materials was performed by an excavator and the materials were spread and leveled by a grader in the designated area. The compaction was done by a 13-tonnes smooth steel drum roller and a layer thickness of 300mm was adopted.

At the end of each compacted layer, in-situ density was routinely monitored. A total of 37 sand cone replacement (SCR) and 34 nuclear densometer (ND) tests were performed. To assess the strength of the mixtures along the depth of compaction layers, 6 Dynamic Cone Penetration Tests (DCPTs) were performed in accordance to ASTM D6951 (three tests for each mixture), and the location of these tests are shown in Fig. 1. In this test the number of blows required to drive the cone penetrometer $100 \mathrm{~mm}$ into the compacted layers was measured throughout the test. Finally, the equivalent in-situ CBR (ASTM D6951) was calculated from the measured penetration as follows,

$$
C B R=292 / D C P^{1.12}
$$

where DCP is the penetration per blow ( $\mathrm{mm} / \mathrm{blow})$.

A total of four Plate Load Tests (PLTs) were conducted for assessing the deformation behavior of the mixtures in two stages. The first and second stages were 30 and 170 days after compaction, respectively. The reason for the two stages of PLT was to assess the variation of the pressure-settlement behavior of the mixtures induced by the chemical reactions associated with BOS already reported in laboratory tests (Rujikiatkamjorn et al., 2012). The tests were conducted using 300mm diameter rigid circular plate in accordance with ASTM D1194. The reaction was provided by a heavy truck and the load was applied through a hydraulic jack. Three dial gauges were used in a triangle pattern to measure displacement (to accuracy of $0.01 \mathrm{~mm}$ ) and they were fixed to a reference beam (Fig. 3a). For each loading increment, the settlements were measured at fixed time intervals and the load was maintained until the change in settlement was less than $0.01 \mathrm{~mm} / \mathrm{min}$.

After compaction, 12 steel rods (300mm long) were installed into the compacted layer in a hexagonal pattern and acted as surveying pins for monitoring the vertical expansion with time (Fig. 1). Each rod was embedded $200 \mathrm{~mm}$ into the layer and protruded $100 \mathrm{~mm}$ above the top surface. The variation of the level of the steel rods was measured in relation to a surface benchmark for 6 months. Initially, the readings were taken weekly and then the time intervals were increased to monthly basis. 

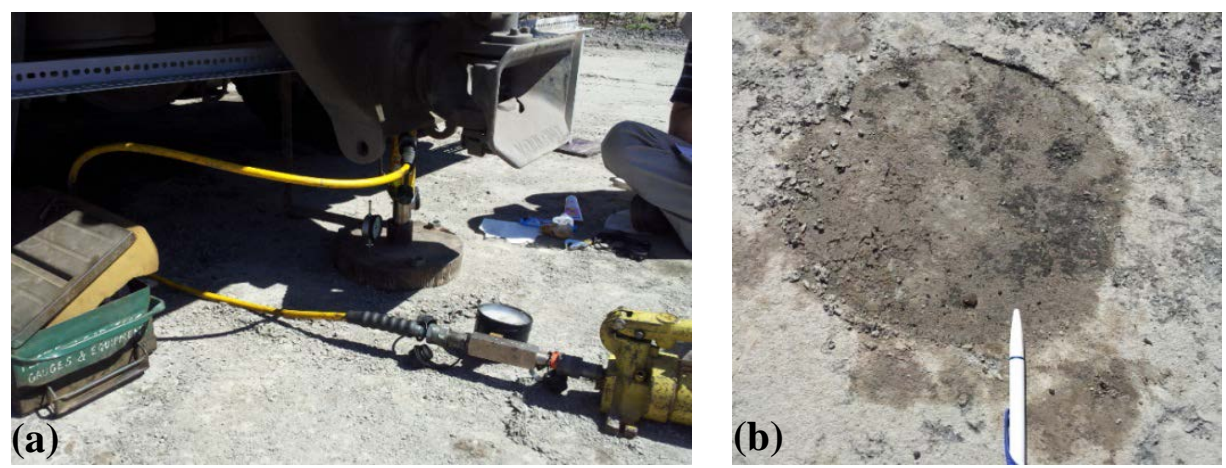

FIG 3. (a) Plate load test setup in the field trial (b) Settlement on the surface after plate load test

\section{RESULTS AND DISCUSSION}

\section{Field compaction}

Fig. 4 shows the results obtained during compaction in terms of dry unit weight and moisture content from the SCR and ND tests. Since the moisture contents of the specimens from ND were unreliable, the average moisture content from SCR specimens was taken for the calculation of ND specimens. The maximum dry unit weight (MDUW) from laboratory tests for CW43-BOS57 and CW27-BOS73 were 20.21 and $21.13 \mathrm{kN} / \mathrm{m}^{3}$, respectively. The lines corresponding to $90 \%, 95 \%$, and $100 \%$ of relative MDUW were also plotted for comparison. Fig. 4 shows that for both mixtures, four roller passes are sufficient to reach $90 \%$ relative compaction and further passes had insignificant influence on the dry unit weight. The in-situ dry unit weight of CW43-BOS57 was in the range of $16.5-20 \mathrm{kN} / \mathrm{m}^{3}$ while for the CW27BOS73 was $18.9-20.9 \mathrm{kN} / \mathrm{m}^{3}$. The higher value for the latter mixture is due to the higher content of BOS which has higher specific gravity compared to CW (Table 1).
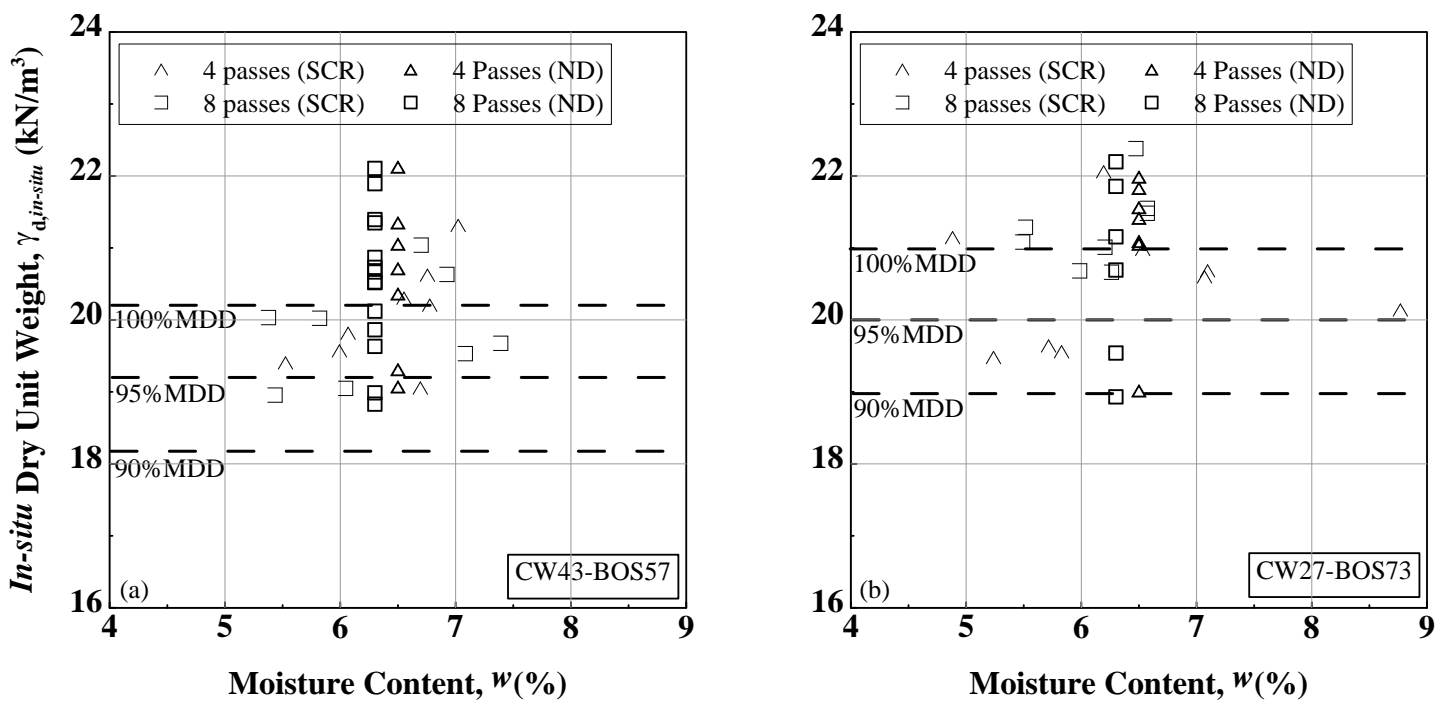

FIG 4. Field dry unit weight and moisture content determined by SCR and ND for (a) CW43-BOS57 and (b) CW27-BOS73 


\section{Dynamic cone penetration (DCP)}

The results of the DCPTs are presented in Fig. 5. As it was expected, at shallow depth $(<300 \mathrm{~mm})$, the equivalent in-situ CBR values were small due to the low confinement. However, for greater depths, the CBR value increased significantly up to layer 2. In layer 1, there was a decrease in CBR that might be attributed to poor compaction within that layer. Although the results of the DCPT for the two mixtures were similar (i.e. increased with depth), the CBR values of CW43-BOS57 were slightly higher and more scattered than those of CW27-BOS77. This could be due to the existence of larger particles of $\mathrm{CW}$, which implies that the cone penetration could have been impeded by the larger particles. By comparing the equivalent in-situ CBR values with the other conventional fill such as dense to very dense sand which is in a range of 25-50 (Look, 2007), these mixtures may be considered suitable to be used as structural fill in terms of shear strength.

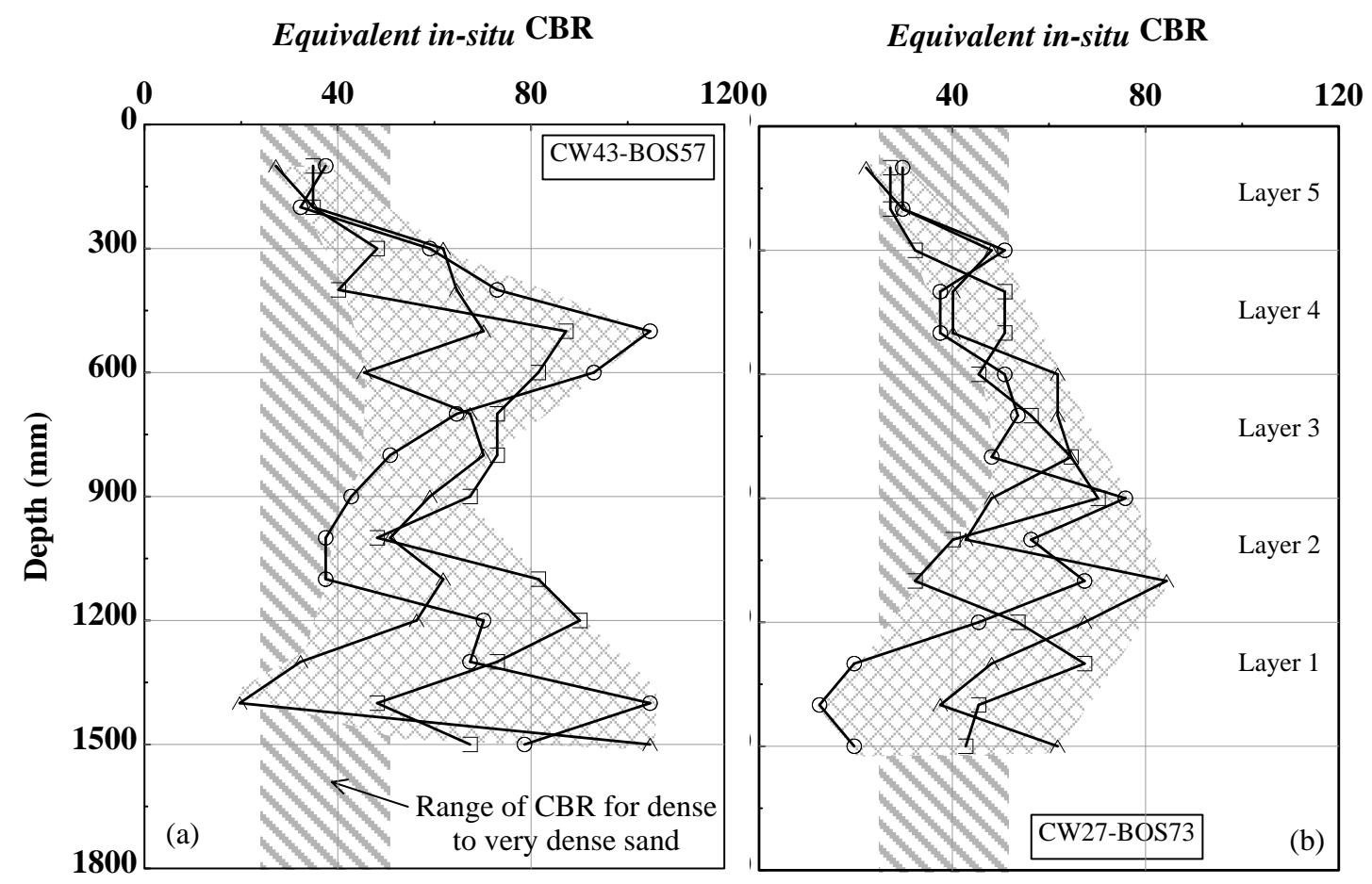

FIG 5. Variation of the equivalent in-situ CBR with depth for (a) CW43-BOS57 and (b) CW27-BOS73

\section{Plate load test}

A total of four Plate Load Tests (PLTs) were carried out on the mixtures to monitor the settlement performance of the mixtures under loading. Two tests for each mixture were performed at two different times to investigate the effects of chemical reaction on the strength due to the presence of free lime $(\mathrm{CaO})$ and free magnesium $(\mathrm{MgO})$ in the BOS. The variation of applied pressure with settlement, for the two stages (i.e. 30 and 170 days after compaction) is plotted in Fig. 6. 
It was evident that the yielding did not occur for the maximum pressure applied (i.e. $1000 \mathrm{kPa}$ ). Therefore, the maximum load bearing capacity could not be defined from these tests. Furthermore, these mixtures underwent swelling with time, that caused a crust type layer to be formed on the surface, and thus a sitting pressure equal to $400 \mathrm{kPa}$ was identified in the results of the second stage. Under low pressure, this layer prevented the propagation of stress in the underlying layer. As it can be observed, beyond this pressure level $(400 \mathrm{kPa})$ the pressure-settlement curve is governed by the elastic response (i.e. unloading-reloading stages follow the same line). From the results of the unloading-reloading stages, the modulus of reaction in the elastic region $\left(\mathrm{K}_{\mathrm{s}}\right)$ for CW43-BOS57 and CW27-BOS73 were 5.60 and 10.80 $\mathrm{MPa} / \mathrm{mm}$, respectively.

The results showed that under typical port loading condition which is $50 \mathrm{kPa}$ live load (Lai et al., 2011) to $120 \mathrm{kPa}$ (that can be increased in future), the settlement of the two mixtures would be less than $1 \mathrm{~mm}$ (Fig. 3b). Therefore, these mixtures demonstrated suitability to be used as structural fill in terms of settlement. The strength gain with time was more significant for the mixture with higher BOS content (CW27-BOS73). For instance, the settlements under 500kPa applied pressure for the mixture CW27-BOS73 at the 30 and 170 days were $6.0 \mathrm{~mm}$ and $2.3 \mathrm{~mm}$, whereas for CW43-BOS57 were approximately $7.2 \mathrm{~mm}$ and $7.5 \mathrm{~mm}$, respectively (the settlement under the plate after removal was hardly visible as shown in Fig. 3b).

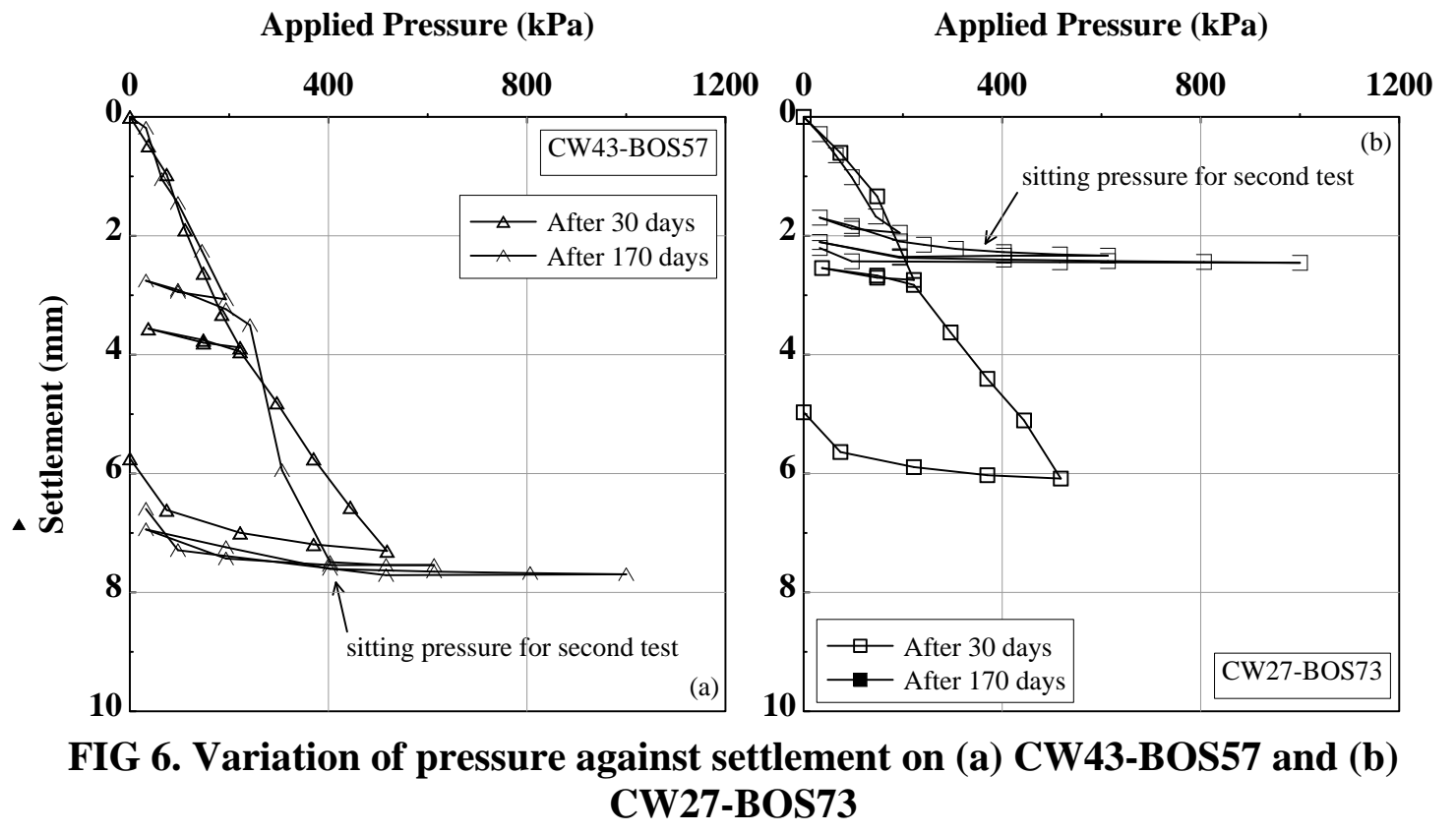

\section{Swell potential}

The swell potential, which is the ratio of vertical expansion to the layer thickness in percentage, was determined by surveying, and the results are plotted in Fig. 7. As expected, the mixture with higher BOS content showed more swelling due to the higher content of $\mathrm{CaO}$ and $\mathrm{MgO}$. After 154 days, the swelling potential for CW43BOS57 and CW27-BOS73 were 6.3\% and 5\%, respectively. Since the vertical 
expansion of BOS requires moisture for hydration, the rate of swelling potential increased significantly between 15 and 35 days due to continuous rainfall for several days.

Although the swelling potential of the mixture is an unfavorable point for these materials, any surcharge applied (e.g. pavement, live loads) would reduce the vertical expansion substantially as it was reported by Wang et al., 2010). In fact, provided that the applied load exceeds the swell pressure (usually determined in the laboratory) no vertical expansion would occur.

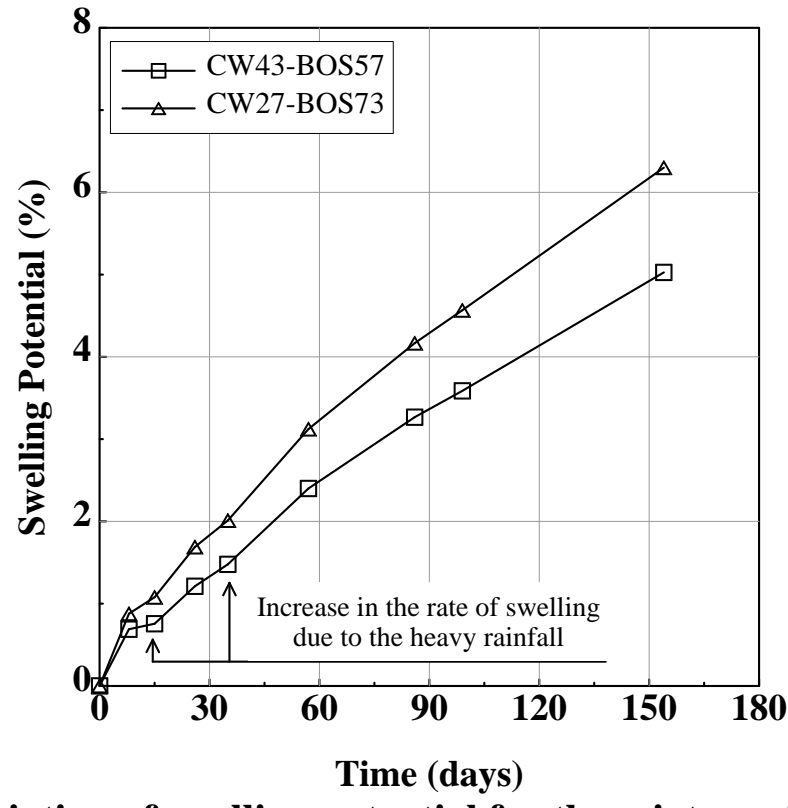

FIG 7. Variation of swelling potential for the mixtures in the field.

\section{CONCLUSIONS}

Field performance of two CW and BOS mixtures were evaluated and discussed by conducting DCPTs, PLTs, and swell monitoring. The two selected mixtures were identified through laboratory studies as suitable reclamation fill. The following conclusions were extracted from this study:

(1) It was observed that a minimum 4 passes of a 13-tonne vibratory smooth roller was adequate to compact the mixtures to the dry unit weight exceeding $90 \%$ relative compaction. Further passes had insignificant effect on the final dry unit weight of the mixtures.

(2) The results of DCPT on the mixtures showed that the average equivalent insitu CBR was between 46 and 60 . This implies that the shear and compression strength of the compact CW-BOS mixtures was adequate to be qualified as a structural fill.

(3) The results of the PLT indicated that the settlement-deformation of the compacted CW-BOS mixtures decreased with time due to hydration of BOS component. The increase in the compression strength was more significant in the mixture with a higher BOS content. For this mixture, the vertical settlement under $500 \mathrm{kPa}$ applied pressure decreased from $6.0 \mathrm{~mm}$ to $2.3 \mathrm{~mm}$. 
(4) Although the two mixtures exhibited promising results in terms of strength and settlement behavior, the vertical expansion was $6.3 \%$ and $5 \%$ due to the existence of $\mathrm{CaO}$ and $\mathrm{MgO}$ in the $\mathrm{BOS}$ fraction.

The field investigation confirmed that the compacted mixtures of CW-BOS had similar properties to conventional sandy fills in terms of dry unit weight and shear strength, to be used for reclamation projects. However, the BOS content in the mixture should be limited due to its swelling potential, and further laboratory investigation is essential to establish the swell pressure for different mixtures, so that long term stability can be ensured.

\section{ACKNOWLEDGMENTS}

The authors acknowledge the financial assistant by the Australian Research Council and the industrial partners Port Kembla Port Corporation, BHP Billiton-Illawarra Coal, Douglas Partners, Coffey Geotechnics, Menard Bachy, and Australian Steel Mill Services. The assistance of A/Prof Cholachat Rujikiatkamjorn, Chazath Kaliboullah and Fernando Escribano in executing field trial tests is gratefully appreciated.

\section{REFERENCES}

ASTM (1998). D1194-94: "Standard test method for bearing capacity of soil for static load and spread footings", West Conshohocken, PA, USA.

ASTM (2009). D6951/D6951M: "Standard test method for use of the dynamic cone penetrometer in shallow pavement application", West Conshohocken, PA, USA.

Australian Standard (AS) 1289.3.6.1-2009: "Methods of testing soils for engineering purposes - Soil compaction and density tests - Determination of the particle size distribution of a soil - Standard method of analysis by sieving".

Chiaro, G., Indraratna, B. \& Tasalloti, S. M. A. (2014a). "Predicting the Behaviour of Coal Wash and Steel Slag Mixtures under Triaxial Conditions." Canadian Geotechnical Journal, DOI: 10.1139/cgj-2013-0476 (in press, available online).

Chiaro, G., Indraratna, B., Tasalloti, S. M. A. \& Rujikiatkamjorn, C. (2014b). "Optimisation of coal wash-slag blend as a structural fill." Ground Improvement, DOI: 10.1680/grim.13.00050 (in press, available online).

Indraratna, B. (1994). "Geotechnical Characterization of Blended Coal Tailings for Construction and Rehabilitation Work." Quarterly Journal of Engineering Geology and Hydrogeology, 27, 353-361.

Indraratna, B., Rujikiatkamjorn, C. \& Chiaro, G. (2012). "Characterization of Compacted Coal Wash As Structural Fill Material." Geotechnical Special Publication ASCE, GSP 225, 3826-3834.

Lai, Z., His, J., Rheinberger, T. \& Andrews, T. (2011). "Geotechnical offshore site investigation and reclamation design at Port Kembla." Proceedings of Australian Geomechanics Society - Sydney Symposium, Coastal and Marine 
Geotechnics: Foundations and Trade. Sydney, Australia.

Leventhal, A. (1996). "Coal washery Reject as an Engineered Material." National Symposium on the Use of Recycled Materials in Engineering Construction. Sydney, NSW.

Look, B. (2007). Handbook of Geotechnical Investigation and Design Tables, Taylor $\&$ Francis.

Malasavage, N., Jagupilla, S., Grubb, D., Wazne, M. \& Coon, W. (2012). "Geotechnical Performance of Dredged Material-Steel Slag Fines Blends: Laboratory and Field Evaluation." Journal of Geotechnical and Geoenvironmental Engineering, 138, 981-991.

Rujikiatkamjorn, C., Indraratna, B. \& Chiaro, G. (2013). "Compaction of coal wash to optimise its utilisation as water-front reclamation fill." Geomechanics and Geoengineering, 8, 36-45.

Rujikiatkamjorn, C., Indraratna, B., Chiaro, G., Naeeni, S. \& Tasalloti, S. M. A. (2012). "Compaction and strength testing of industrial waste blends as potential port reclamation fill." In: Narsilio, G. A., Arulrajah, A. \& Kodikara, J. (eds.) 11th Australia - New Zealand Conference on Geomechanics: Ground Engineering in a Changing World. Melbourne, Australia.

Wang, G., Wang, Y. \& Gao, Z. (2010). "Use of Steel Slag as a Granular Material: Volume Expansion Prediction and Usability Criteria." Journal of Hazardous Materials, 184, 555-560. 